\title{
Rupture of a True Aneurysm of the Posterior Meningeal Artery at Its Anomalous Origin from the Internal Carotid Artery: Case Report
}

\author{
Jawad Tadili1*, Nabil Moatassim Billah², Meryem Fikri³ ${ }^{3}$ Moulay Rachid El Hassani3, \\ Ittimad Nassar ${ }^{2}$, Ali Kettani' ${ }^{1}$ Mamoun Faroudi'
}

\author{
${ }^{1}$ Mohammed V University, Emergency and Intensive Care Unit, Ibn Sina Hospital, Rabat, Morocco \\ ${ }^{2}$ Mohammed V University, Central Radiology, Ibn Sina Hospital, Rabat, Morocco \\ ${ }^{3}$ Mohammed V University, Neuroradiology Service, Specialties Hospital, Rabat, Morocco \\ Email: tadilij@gmail.com
}

How to cite this paper: Tadili, J., Billah, N.M., Fikri, M., El Hassani, M.R., Nassar, I., Kettani, A. and Faroudi, M. (2016) Rupture of a True Aneurysm of the Posterior Meningeal Artery at Its Anomalous Origin from the Internal Carotid Artery: Case Report. Open Journal of Clinical Diagnostics, 6, 36-41.

http://dx.doi.org/10.4236/ojcd.2016.63007

Received: August 24, 2016

Accepted: September 18, 2016

Published: September 21, 2016

Copyright $\odot 2016$ by authors and Scientific Research Publishing Inc. This work is licensed under the Creative Commons Attribution International License (CC BY 4.0).

http://creativecommons.org/licenses/by/4.0/

\section{Abstract}

The posterior meningeal artery (PMA) usually originates from the third segment of the vertebral artery. Many variations in its origin and course have been observed; however, as far as we know, the association of true aneurysm of the PMA and its anomalous origin from the internal carotid artery has not been reported previously. We reported the case of a 59-year-old woman who suddenly presented a loss of consciousness without head trauma, computed tomography (CT) revelated intracerebellous hematoma associated with a subarachnoid hemorrhage of the posterior cerebral fossa. Cerebral angiography demonstrated a true aneurysm of the PMA which originated from the internal carotid artery.

\section{Keywords}

Non Traumatic True Aneurysm, Posterior Meningeal Artery (PMA), Internal Carotid Artery, Subarachnoid Hemorrhage, Intracerebellar Hematoma

\section{Introduction}

The PMA is the main menigeal artery of the posterior cerebral fossa, and some variations in its origin, course and ansatomosis have been reported previously. Embryogenesis anomalies are usually evocated in such situations.

Aneurysms of meningeal arteries represent a rare entity among the vascular abnormalities of the central nervous system.

True aneurysms of the posterior circulation are less common than those of the ante- 
rior circulation, and involvement of the posterior meningeal artery is even more unusual. Previous reports have implicated trauma, anomalous origin from the posterior inferior cerebellar artery and dural arteriovenous fistula, as causes of true PMA aneurysms.

The coexistence of anomalous origin of the PMA and a non-traumatic aneurysm in its intracranial segment suggests a constitutional origin of the two anomalies.

However, the haemodynamic stress associated with this rare vascular pattern could be a possible mechanism of aneurysm formation in this case.

The clinical expression of these aneurysms is variable and is manifested by a subarachnoid hemorrhage subdural or intra parenchymal hematoma.

The therapeutic management is not clearly codified. Recently endovascular therapy has been proposed as an alternative to the conventional surgical treatment [1].

We present here the first reported association of true PMA aneurysms with unusual anatomical variation of the posterior meningeal artery arising from the internal carotid.

\section{Case}

A 59 year-old-woman, with medical history of obesity (body mass index of 35) and high blood pressure, admitted to emergency for sudden loss of consciousness without any notion of skull trauma.

The admission Neurological examination objected a Glasgow Coma Scale (GCS) at 9/15 (eye opening 2, verbal response 2, motor response 5), without sensitive-motor deficit, the pupils were equal and reactive.

Cerebral computed tomography revealed a subcortical hematoma of the right cerebellar hemisphere surrounded by a perilesional edema, associated with a SAH in the fourth ventricule and the prepontine cistern without hydrocephalus (Figure 1).

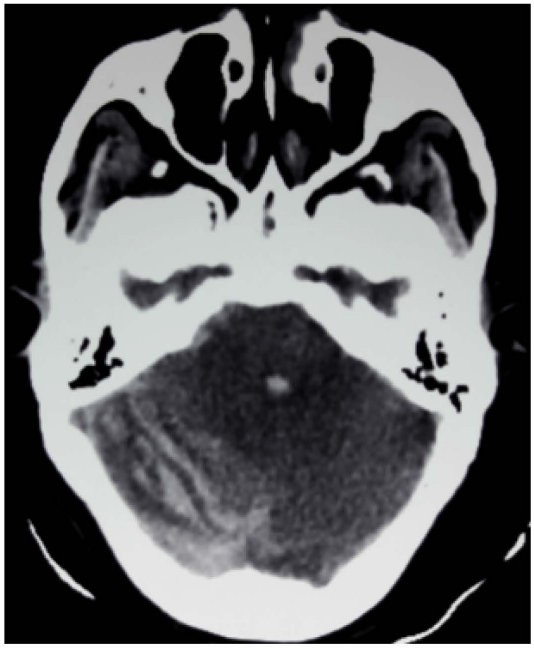

(a)

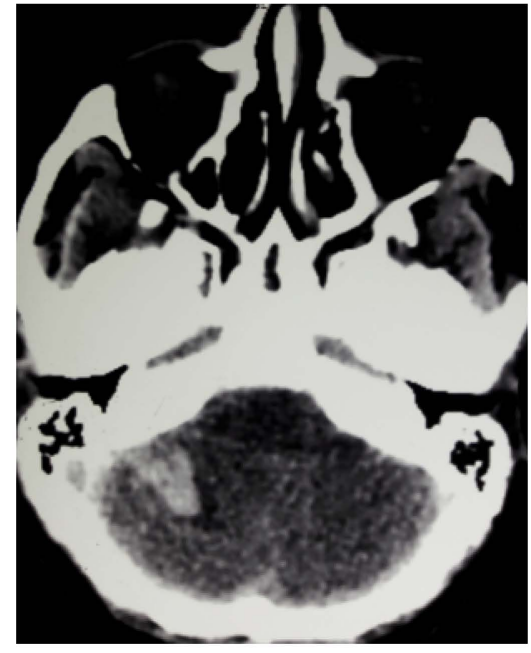

(b)

Figure 1. Brain computed tomography: (a) subarachnoid hemorrhage of furrows of right cerebellar hemisphere, the prepontine cistern and the fourth ventricle; (b) hematoma of the right cerebellar hemisphere. 
The patient was transferred in intensive care unit where sedation and invasive ventilation were started, and she was placed under methyl prednisolone and nimodipine.

Digital Angiography was performed. The right selective internal carotid opacification showed the birth of a posterior meningeal artery from the last segment of the cervical portion of the right internal carotid artery (Figure 2(a) and Figure 2(b)).

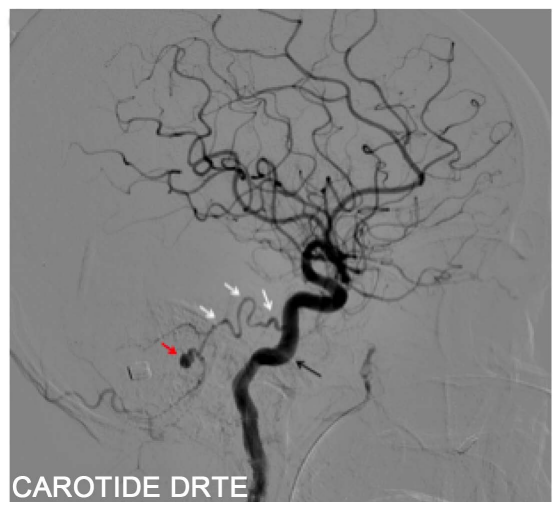

(a)

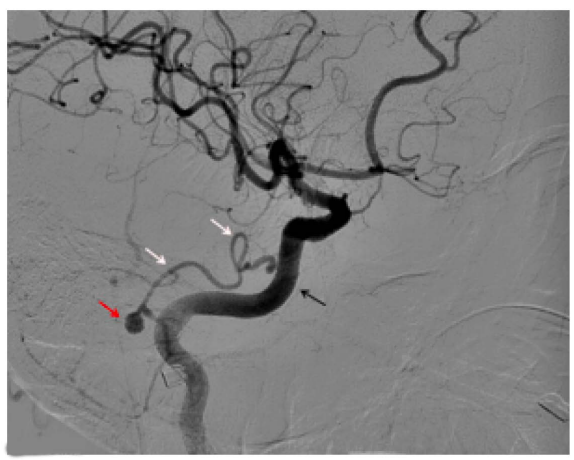

(b)

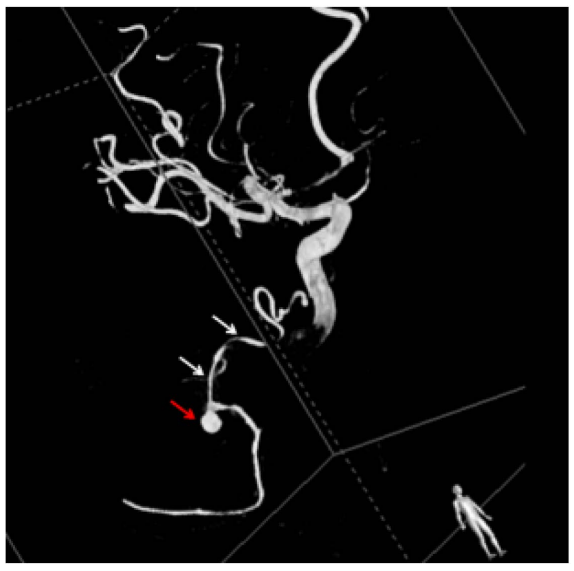

(c)

Figure 2. Angiography of the right internal carotid in profile incidence (a); oblique incidence (b) with $3 \mathrm{D}$ reconstruction $(\mathrm{c})$, showing a posterior meningeal artery (white arrow), arising from the internal carotid artery (black arrow), at the last segment of its cervical portion with a saccular aneurysm (red arrow), powered by the posterior meningeal artery. 
The angiography objected also a saccular pedicled aneurysm arising from the posterior meningeal artery, measuring $4.8 \times 4.5 \mathrm{~mm}$ (Figures $2(\mathrm{a})$-(c)). Embolization of the aneurysm could not be performed because of the technical failure of hyperselective catheterization of the posterior meningeal artery.

Surgical treatment of the aneurysm was suggested, unfortunately the patient died the day before by a sever pulmonary embolism, despite a prophylaxis by mechanical measurements, probably because of the high thrombo embolic risk related to her obesity and her cerebral hemorrhagic pathology delaying the introduction of anticoagulants in the initial phase.

\section{Discussion}

Aneurysms of the posterior meningeal artery are rare and can be of 2 types: true aneurysms and pseudoaneurysms.

The origin and the incidence of true aneurysms remain poorly understood. Congenital anomalies [2], Paget's disease [3] and hypertension [3] [4] are the main etiologies cited in the literature.

Other pathological situations can support the development of true aneurysms such as, dural arteriovenous malformations [5], meningiomas [6], hemangioblastomas [7] and angiomas [8] of the central nervous system.

Head trauma is the primary cause in the development of pseudoaneurysms of meningeal arteries, and the association at a skull fracture is present in $70 \%$ to $90 \%$ [9].

False aneurysms are known to have specific characteristics on angiography which include peripheral location, absence of neck and a delayed opacification during the angiogram.

These features explain why traumatic meningeal pseudoaneurysms are usually visible only in the late injection stages of the angiography [9]-[11].

The rarity of diagnosed cases of non traumatic true aneurysms of meningeal arteries may be explained by the protection offered to the aneurysm by the dura internally and the skull externally. Also, Hassler suggests that the defect of the media is smaller in the meningeal arteries compared to cerebral arteries [12].

Berk [2] and New [3] reported the first cases of true aneurysm of a meningeal artery. Both of the 2 cases were aged women and had Paget disease and hypertension without history of head trauma. The aneurysm was located at the proximal part of the middle meningeal artery in both cases.

The abnormal origin of the PMA is the second peculiarity of our case. The posterior meningeal artery, born usually from the third segment of the vertebral artery, enters the skull through the foramen magnum [13]. More rarely it can arise from the ascending pharyngeal artery, branch of the external carotid [14].

Its origin from an artery supplying the brain parenchyma can result from the persistence of the preexisting anastomotic channels between the primitive cerebral and meningeal vessels, and regression of the proximal stem of the posterior meningeal artery [15]. 
To our knowledge, only one case [16] of PMA arising from the internal carotid artery has been reported in the literature till now.

In our patient's case, the coexistence of a rare anatomical variation and a true aneurysm of the PMA pushed us to search systematically for other vascular malformations. It is likely that the combination of histopathological features and hemodynamic properties brought these two entities in conjunction.

There are no definite treatment guidelines for true aneurysms of the PMA because of the rareness of publications based on case reports. Both surgical and endovascular therapies have been performed successfully. Surgery should be considered if associated lesions such as tumor, AVM, or angioma are identified.

\section{Conclusions}

The prognosis of a ruptured non-traumatic aneurysm of a meningeal artery is not clearly assessed in the literature, but has been reported to be generally better than traumatic pseudoaneurysm [17]. However, the mortality seems to be impacted by the underlying disease and the cerebral tissular damage.

The occurrence of such hemorrhagic events in the cerebral posterior fossa suggests that the exclusion treatment should be performed without delay.

\section{Conflict of Interest}

On behalf of all authors, the corresponding author states that there is no conflict of interest.

\section{References}

[1] Goetz, F., Lanfermann, H., Nakamura, M., Krauss, J.K. and Hong, B. (2011) Life-Threatening Hemorrhage from a Traumatic Aneurysm of the Posterior Meningeal Artery: Treatment with Coil Embolization. Central European Neurosurgery, 72, 162-165. http://dx.doi.org/10.1055/s-0030-1253347

[2] Berk, M.E. (1961) Aneurysm of the Middle Meningeal Artery. The British Journal of Radiology, 34, 667-668. http://dx.doi.org/10.1259/0007-1285-34-406-667

[3] New, P.F. (1967) True Aneurysm of the Middle Meningeal Artery, Cranial Paget's Disease and Hypertension: A Triad. Clinical Radiology, 18, 154-157. http://dx.doi.org/10.1016/S0009-9260(67)80008-4

[4] Sandin III, J.A., Salamat, M.S., Baskaya, M., et al. (1999) Intracerebral Hemorrhage Caused by the Rupture of a Nontraumatic Middle Meningeal Artery Aneurysm: Case Report and Review of the Literature. Journal of Neurosurgery, 90, 951-954. http://dx.doi.org/10.3171/jns.1999.90.5.0951

[5] Kahara, VJ. (1999) Middle Meningeal Artery Aneurysm: Case Illustration. Journal of Neurosurgery, 91, 518. http://dx.doi.org/10.3171/jns.1999.91.3.0518

[6] O’Neill, O.R., Barnwell, S.L. and Silver, D.J. (1995) Middle Meningeal Artery Aneurysm Associated with Meningioma: Case Report. Neurosurgery, 36, 396-398. http://dx.doi.org/10.1227/00006123-199502000-00022

[7] Raygor, K.P., Rowland, N.C., Cooke, D.L., Solomon, D.A. and Huang, M.C. (2014) Aneurysm of the Posterior Meningeal Artery Embedded within a Dorsal Exophytic Medullary 
Hemangioblastoma: Surgical Management and Review of Literature. Journal of Cerebrovascular and Endovascular Neurosurgery, 16, 293-298.

http://dx.doi.org/10.7461/jcen.2014.16.3.293

[8] Jin, K.H., Toyoda, S., Kumagai, K., Hashimoto, T., Abe, Y. and Suzuki, K. (1981) NonTraumatic Middle Meningeal Aneurysm and Angioma in a Child. Brain and Development, 3, 323-328. http://dx.doi.org/10.1016/S0387-7604(81)80055-1

[9] Lee, J.Y., Lee, C.Y. and Kim, H.W. (2014) Angiographically Progressive Change of Traumatic Pseudoaneurysm Arising from the Middle Meningeal Artery. Journal of Korean Neurosurgical Society, 56, 423-427.

[10] Higazi, I., El-Banhawy, A. and El-Nady, F. (1969) Importance of Angiography in Identifying False Aneurysm of the Middle Meningeal Artery as a Cause of Extra-Dural Hematoma. Case Report. Journal of Neurosurgery, 30, 172-176.

http://dx.doi.org/10.3171/jns.1969.30.2.0172

[11] Kim, J.H., Yim, M.B., Lee, C.Y. and Kim, I.M. (2001) Surgical Management of Pseudoaneurysm. Journal of Korean Neurosurgical Society, 30, 307-318.

[12] Hassler, O. (1962) Medial Defects in the Meningeal Arteries. Journal of Neurosurgery, 19, 337-340. http://dx.doi.org/10.3171/jns.1962.19.4.0337

[13] Masanori, T., Kiyoshi, K., Hiroshi, A., Minoru, I., Tomonobu, K., Kouhei, N., Shuko, M., Housei, E., Kimiya, S. and Akira, T. (2007) Development of Unusual Collateral Channel from the Posterior Meningeal Artery after Endovascular Proximal Occlusion of the Posterior Inferior Cerebellar Artery. Neurologia Medico-Chirurgica ( Tokyo), 47, 503-505. http://dx.doi.org/10.2176/nmc.47.503

[14] Hsu, C.-Y., Sheu, J.-J., Huang, K.-M. and Li, Y.-W. (2001) Bilateral Anomalous Origins of the Posterior Meningeal Artery from the Ascending Pharyngeal Arteries. Journal of Neurosurgery, 28, 123-125.

[15] Tanohata, K., Maehara, T., Noda, M., Sugiyama, S. and Okazaki, A. (1987) Anomalous Origin of the Posterior Meningeal Artery from the Lateral Medullary Segment of the Posterior Inferior Cerebellar Artery. Neuroradiology, 29, 89-92. http://dx.doi.org/10.1007/BF00341048

[16] Kwak, S., Nagashima, T. and Kobayashi, S. (1980) Anomalous Origin of the Posterior Meningeal Artery from the Internal Carotid Artery. Neuroradiology, 19, 103-104. http://dx.doi.org/10.1007/BF00342604

[17] Srinivasan, A., Lesiuk, H. and Goyal, M. (2006) Spontaneous Resolution of Posttraumatic Middle Meningeal Artery Pseudoaneurysm. American Journal of Neuroradiology, 27, 882883. 
Submit or recommend next manuscript to SCIRP and we will provide best service for you:

Accepting pre-submission inquiries through Email, Facebook, LinkedIn, Twitter, etc. A wide selection of journals (inclusive of 9 subjects, more than 200 journals)

Providing 24-hour high-quality service

User-friendly online submission system

Fair and swift peer-review system

Efficient typesetting and proofreading procedure

Display of the result of downloads and visits, as well as the number of cited articles

Maximum dissemination of your research work

Submit your manuscript at: http://papersubmission.scirp.org/

Or contact ojcd@scirp.org 